\title{
Bipolar resectoscope: the future perspective of hysteroscopic surgery
}

\author{
Luca Mencaglia • Emmanuel Lugo • Sabina Consigli • \\ Cristiana Barbosa
}

Received: 30 January 2008 / Accepted: 15 April 2008 /Published online: 24 May 2008

(C) Springer-Verlag 2008

\begin{abstract}
The objective of this study is to prove the effectiveness and security of bipolar resectoscope in hysteroscopic surgery. A clinic-based, prospective, nonrandomised trial was conducted in Centro Florence di Chirurgia Ambulatoriale, Florence, Italy. One hundred fifty-seven women with endocavitary uterine pathologies, such as myoma, polyp, uterine septum and endometrial hyperplasia, were included in the study. Myomectomy, polypectomy, metroplasty and endometrial ablation have been done through the use of Karls Storz 26 Fr bipolar resectoscope and Autocon II 400 high-frequency unit with parameters standard selected 180 (in effect 4) for cut and 120 (in effect 4). The main outcome measures are the current flow, distension media, tissue alteration, bleeding during resection, visibility and cost. Cutting power and coagulations appears sensibly better in comparison with monopolar resection, thanks to plasma effect. The vision during resection is not disturbed by the presence of the technical characteristics of the instruments. Results in terms of time of surgery, intra-operatory bleeding and complete removal of the pathology were better compared with traditional monopolar resection. There were no complications with bipolar resection thanks to use of saline solution
\end{abstract}

\footnotetext{
L. Mencaglia $\cdot$ E. Lugo $(\bowtie) \cdot$ S. Consigli $\cdot$ C. Barbosa

via di Careggi 38,

Florence 50139, Italy

e-mail: emmanuel.lugo@centroflorence.it

L. Mencaglia

e-mail: luca.mencaglia@centroflorence.it

S. Consigli

e-mail: sabina.consigli@centroflorence.it

C. Barbosa

e-mail: cristiana.barbosa@centroflorence.it
}

as distention media. The bipolar resectoscope presents some advantages in comparison with the monopolar such as: better cut and coagulation by plasma effect of bipolar current, minor risks with the use of saline solution, lower alterations of the tissue, less bleeding during resection, better visibility and reduced cost.

Keywords Hysteroscopy · Bipolar resectoscope . Hysteroscopic surgery

\section{Introduction}

The gynaecological resectoscope, born from its urological equivalent, is commonly used in gynaecological practice to resect or remove intra-cavitary pathology and also to perform endometrial ablation. The resectoscope consists of a telescope ( 2.9 and $4 \mathrm{~mm}$, preferably with a $12^{\circ}$ angle of view to always keep the loop within the viewing field), an electrical loop to perform passive cuts and two sheaths for continuous flow suction and irrigation of liquid distension medium. Besides the cutting loop, other instruments such as micro-knives or series of coagulation or vaporisation electrodes of various shapes can be connected to the resectoscope.

There are essentially two types of resectoscopes which differ in outer diameter: 7.5 and $9.2 \mathrm{~mm}$. The $7.5-\mathrm{mm}$ resectoscope should be used in case of narrow cervical canal or difficult dilatation; the $9.2 \mathrm{~mm}$ resectoscope allows to perform major surgery [1].

Electrosurgery in hysteroscopy

Biological tissue contains a more or less high concentration of electrolytes, making it sufficiently conductive to be 
treated electrosurgically. The thermal effect of high-frequency current is used for separating (cutting) and coagulating tissue (desiccation of tissue). The high-frequency currents must be used on the patient since lowfrequency currents can stimulate nerve and muscle cells in the currents flow due to electrochemical processes (electrolysis). These effects are small enough to be disregarded with frequencies above $100 \mathrm{kHz}$ [2].

Monopolar or bipolar current system can be adopted

Monopolar resectoscope Conventional hysteroscopic surgery uses a monopolar electrocautery system in which the current passes from the active electrode through the patient's body towards the return plate. The distension media used is glycine $1.5 \%$ sorbitol-mannitol (non-electrolyte irrigation fluid). The monopolar resectoscope is connected to monopolar electrosurgery generator of high frequency and automatically controlled by an acoustic alarm system. In a monopolar system, the electrons flows from a electrosurgery generator to active electrode (electrode of the loop). From the electrode, the current flow is transmitted to tissue then to the plate (neutral electrode) and returns to generator. This system is potentially dangerous since the electrons flows through the body, outside the surgeon visual control, before it can return to the generator. The new generators, however, decreased the incidence of electric damage. In these generators, the cut current flow is automatically regulated based on tissue resistance. The unipolar loop can be used as coagulation, cut and combined (coag-cut) current. The coagulation current flow is characterised by intermittent current flow periods, which cause cellular dehydration, resulting in tissue haemostasis. The non-modulated cut flow is a continuous flow, with high intracellular temperature, causing cellular explosion. Nonmodulated flow can be used also for coagulation and it

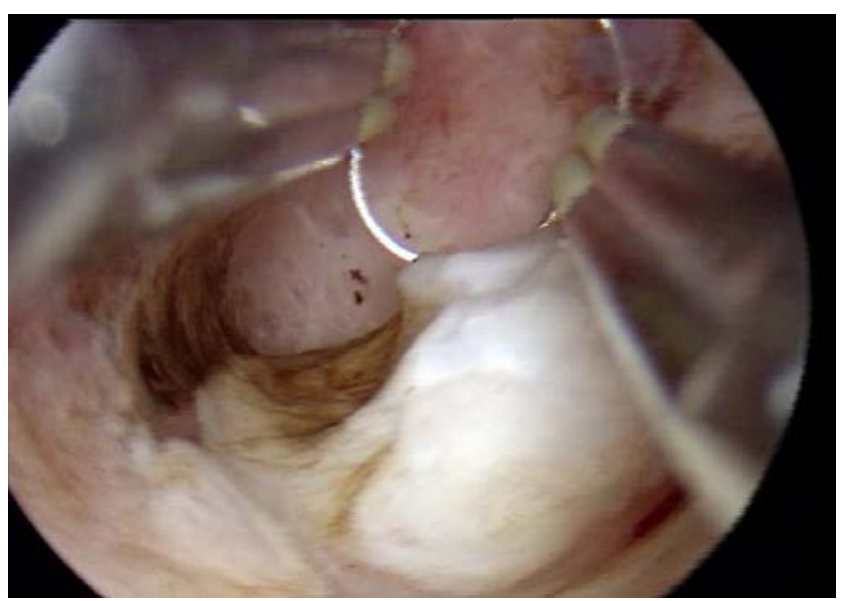

Fig. 1 Endometrial ablation with bipolar resectoscope

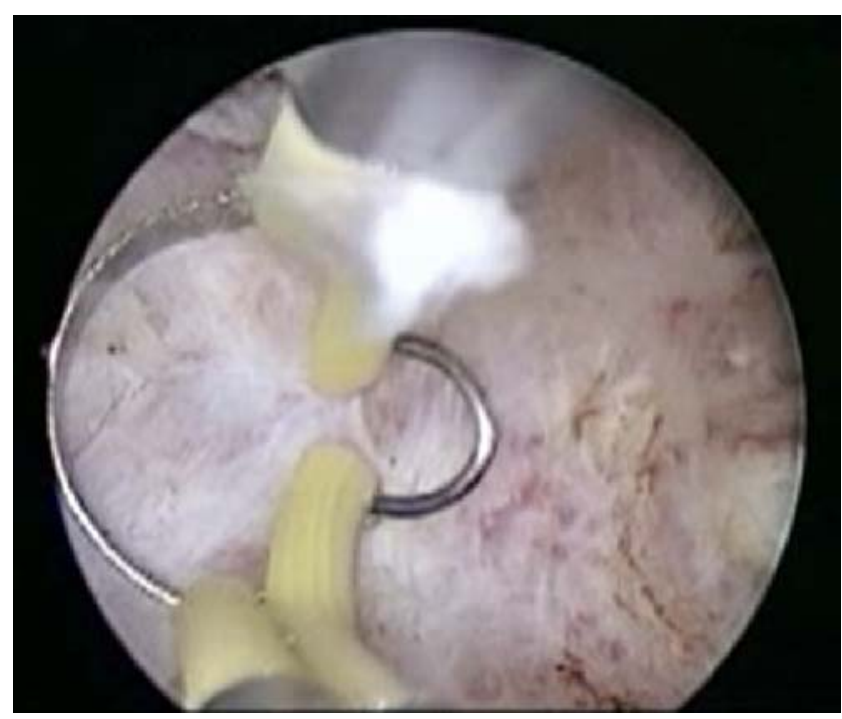

Fig. 2 Metroplasty with bipolar resectoscope

should be preferred because the voltage is lower and continuous [1].

Bipolar resectoscope In bipolar electrosurgery, the current flow through the tissue is restricted to the area between the two electrode's loops that are under visual control of the surgeon (Figs. 1 and 2). In this case, saline solution can be used as distension media because it has no risk of current dispersion. The generator produces a high initial voltage spike that establishes a voltage gradient in a gap between the bipolar electrodes. When the activated bipolar electrode is not in contact with the tissue, the electrolyte solution in the uterus dissipates it. When the loop is sufficiently close to tissue, the high bipolar voltage spike arc between the electrodes converts the conductive sodium chloride solution into a non-equilibrium vapour layer or "plasma effect" containing energy-charged sodium particles. Once formed, this plasma effect can be maintained at lower voltages (100-350 root mean square voltage) [3]. With tissue contact, there is disintegration of tissue via molecular dissociation. Energetic species of the charged ions from the plasma effect result in disruption of carbon-carbon and carbon-nitrogen bonds. There is also electron impact dissociation of water molecules into exited fragments of $\mathrm{H}+$ and $\mathrm{OH}-$ ions. The bottom line is rupture of cell membranes which translates into visible cutting. Clinically, there is a precise tissue effect with minimal collateral damage, as the charged ions have an estimated penetration depth in tissue of only 50 to $100 \mu \mathrm{m}$ $(0.5-1 \mathrm{~mm})[4,5]$. The depth of coagulation is determined principally by the electrode configuration and by the system design, as well as by the technique used by the operator (time and pressure of contact) [6]. 


\section{Subjects}

A series of 157 patients with endocavitary pathologies, previously diagnosed, have been selected in the Centro Florence di Chirurgia Ambulatoriale. This study was performed between September 2005 and February 2006. The pathologies included: uterine myomas G0, G1, G2 (European Society of Gynaecologic Endoscopic classification), endometrial polyps, endometrial hyperplasia without cytological atypia and uterine septums.

\section{Materials and methods}

For all hysteroscopic surgeries, the new working element developed by Karl Storz System, the Autocon II 400 (Fig. 3 ), in bipolar and hysteroscopic function have been used. The parameters' socket used were cutting and coagulation activation type. By using bipolar system in the saline Time$\mathrm{C}$-Cut mode as the saline coagulation mode, the HF voltage form is un-modulated sinusoidal; the rated frequency is 350 $\mathrm{kHz}$ (at $\mathrm{RL}=500 \Omega$ ) $\pm 10 \%$, the crest factor is 1.4 , the rated load resistance is $50 \Omega$, the maxim HF peak voltage is 190 $\mathrm{Vp}$, the maxim power output $370 \mathrm{~W} \pm 20 \%$. The parameter standard used is effect setting 4 for cut and also effect setting 4 for coagulation. The average applied HF power is approximately $130 \mathrm{~W}$ for resection. The bipolar components are compatible with existing resectoscope (optics, sheath). The sheath designed by Karl Storz-Endoskope is electrically completely isolated, the current returns directly via the return electrode and prevents a current flow via the sheath, guarantying a high level of safety. The cutting loops used were GP, GPV, GD, GDV in 24 F. The parameter's electronic irrigation and suction pump were $110 \mathrm{mmHg}$ per $250 \mathrm{ml} / \mathrm{min}$ of flow rate and $75 \mathrm{mmHg} / 0.25$ bar of suction

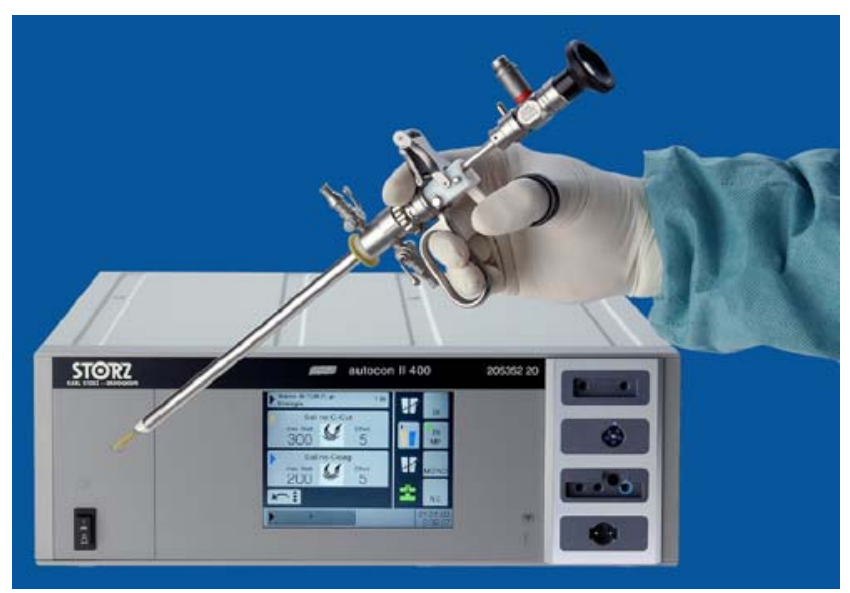

Fig. 3 Autocon II 400
Table 1 Bipolar resection in 157 patients

\begin{tabular}{lcc}
\hline & Number & $>4 \mathrm{~cm}$ \\
\hline Myomas G0 & 19 & 4 \\
Myomas G1 & 35 & 7 \\
Myomas G2 & 20 & 4 \\
Endometrial ablation & 32 & \\
Polyps & 28 & \\
Uterine septum & 23 & \\
Total & 157 & \\
\hline
\end{tabular}

$\mathrm{cm}$ centimeters

pressure. Maximum fluid volume used for patient was 31 . The surgery techniques for each intervention are the same as the one used with the monopolar resectoscope.

\section{Results}

Our preliminary experience in gynaecology consists of 157 patients (Tables 1 and 2) treated by Karls Storz 26 F bipolar resectoscope and Autocon II 400 high-frequency unit with parameters standard selected 180 (in effect 4) for cut and 120 (in effect 4) for coagulation. The resection loops are completely insulated from the sheath of the resectoscope and are reusable loops. Saline solution $(\mathrm{NaCl} 0,9 \%)$ was used as distension medium with no complications. Cutting power and coagulation appears sensibly better in comparison with monopolar resection. In particular, the first cut in case of fibroid tissue does not give any problem, thanks to the plasma effect. Furthermore, the vision during resection is not disturbed by the presence of air bubbles. We included in our series complex cases to evaluate the technical characteristics of the instruments, including an important number of uterine fibroids that in some cases were more than $4 \mathrm{~cm}$ in size and G1 and G2 (partially or totally intramural localisation). Results in terms of time of surgery, intra-operatory bleeding, and complete removal of the pathology were better compared with traditional monopolar resection (Table 3).

Table 2 Patient characteristic

\begin{tabular}{|c|c|c|c|c|}
\hline & Myomectomy & Polypectomy & Metroplasty & $\begin{array}{l}\text { Endometrial } \\
\text { ablation }\end{array}$ \\
\hline $\begin{array}{l}\text { Number of } \\
\text { patients }\end{array}$ & 74 & 28 & 23 & 32 \\
\hline Age & $35.5+3.1$ & $33.2+4.7$ & $32.1+5.3$ & $51.4+8.3$ \\
\hline
\end{tabular}

Values are presented as mean $\pm \mathrm{SD}$ 
Table 3 Peri-operative data

\begin{tabular}{|c|c|c|c|c|}
\hline & $\begin{array}{l}\text { Myomectomy } \\
\text { group }\end{array}$ & $\begin{array}{l}\text { Polypectomy } \\
\text { group }\end{array}$ & $\begin{array}{l}\text { Metroplasty } \\
\text { group }\end{array}$ & $\begin{array}{l}\text { Endometrial } \\
\text { ablation group }\end{array}$ \\
\hline Operative time (min) & $10.6 \pm 1.4$ & $4.8 \pm 2.2$ & $9.5 \pm 2.5$ & $13.2 \pm 3.3$ \\
\hline Complications (intra-operatory-post-operatory-control hysteroscopy) & 0 & 0 & 0 & 0 \\
\hline
\end{tabular}

Values are presented as mean $\pm \mathrm{SD}$

\section{Discussion}

The introduction of bipolar energy in the field of hysteroscopic surgery has meant the beginning of a new age of technology in which the best levels of security and effectiveness will be guaranteed. In 2007, Makris et al. [7] recently reported an experience of 5 years with Gynecare Ethicon bipolar resectoscope in gynaecology, which was used in 59 patients who underwent fibroid resection, evidencing the usefulness of bipolar current to remove small myomas. No complications were reported. In 2000, Loffer FD [8] reported a preliminary experience with the Versa Point bipolar resectoscope in gynaecology, used in 15 patients, vaporising electrode in saline solution distending medium and showing its effectiveness in the removal of submucous myomas. Golan et al. [9] in 2001 reviewed outcomes of operative hysteroscopy, using bipolar electrical energy (Versa Point) in saline solution in 116 women with intrauterine pathology and they proposed this new technique to potential replacement of the monopolar resection. Furthermore, many studies had demonstrated their benefits in urology. Recently, Singh H et al. [10] reported the utility of bipolar system in the transurethral prostate resection (TURP underlined in 2004) and the advantage of the bipolar system in TURP, with the Vista System, and stressed the theoretical benefit of avoiding the risk of TUR syndrome. In our experience and also in the analysis of the published data, it appears very clear that the bipolar resectoscope presents some advantages in comparison with the monopolar.

The current flow through tissue with less post-operative dysuria Wendt-Nordahl [11] et al. is restricted to the area between the two electrode's loops that are under direct vision of the surgeon. Current can be regulated at all times and set to the lowest possible optimal flow of current for minimally invasive treatment. The plasma effect of bipolar current allows better cut and coagulation. In the monopolar technique, the current passes through many tissues outside the surgeon's visual control before it can return to the generator [5, 12]. The risk of thermal injuries at distant organs or tissues, by direct contact of instruments, imperfection of insulation or diffusion of the electric current, is reduced in the bipolar technique [13, 14]. It has minor risk of interference on other electronic equipments (electrocardiogram, pace makers and others) simultaneously connected to the patient [5, 15]. Furthermore, there is reduced stimulation of peripheral nerves including the obturator nerve because there is no current flow through the body of the patient.

Distension media According to Kolmer and Norlen [16] and Koshiba et al. [17], incidence of overflow syndrome in gynaecology and TUR syndrome in urology varies considerably in the literature, ranging from $0.18 \%$ to $10.9 \%$. Mebust et al. [18] reported in 3,885 patients an incidence of $2 \%$ of TUR syndrome. Kudela et al. [19], in 1996, reported the risk of fluid overload syndrome during hysteroscopy monopolar procedure and underlined the necessity to adhere to safety measures which includes selection of a suitable medium (hypotonic electrolyte-free solutionsglycine or sorbitol-mannitol solution), control duration of surgery, respecting correct surgical indications and procedure and specially perform continuous control of balance of the distension medium. Estes and Maye [20] in 2003 stand out the danger of hypotonic, electrolyte-free distension media and their potentiality to be absorbed in volumes large enough to cause hyponatraemia and hypervolaemia. Main concerns in urological and gynaecological conventional monopolar resection is fluid absorption with hyponatraemia, hypervolaemia and glycine toxicity. This syndrome is very dangerous for the patient, leading to neurotoxic coma and death in the worst cases. Most of the morbidities of the overflow syndrome are related to the use of hypotonic nonelectrolyte irrigation fluid. For this reason, close and continuous peri-operative monitoring of the balance of distension medium by a nurse and frequent laboratory investigations are required. Bipolar resection system permits resection using saline solution. The use of saline solution for distension media of the uterine cavity is the principal advantage of this technology so avoid use of hypotonic non-electrolyte solution that can cause fluid overload during the surgical procedure. Saline solutions is easily metabolised, is not toxic and can be used with higher quantity and it is also less expensive than conventional hypotonic nonelectrolyte solutions. Singh et al. [10] in a bipolar versus 
monopolar TURP randomised controlled study reported a significant difference in serum sodium concentration postoperatively. In bipolar TURP, the change in serum sodium was $-1.2 \mathrm{mEq} / 1$ (not different from pre-operative serum $\mathrm{Na}$ concentration), whereas in the monopolar group the mean decrease was $4.6 \mathrm{mEq} / \mathrm{l}$. In three patients, serum $\mathrm{Na}$ was $>125 \mathrm{mEq} / \mathrm{L}$, at risk of TUR syndrome. However, balance of distension medium using saline solution should also be under control. Starkman and Santucci [21] retrospectively reviewed 43 undergoing TURP, 18 consecutive patients treated with the monopolar TURP and 25 with bipolar TURPs. These investigators found an unexpected case of hyponatraemia and pulmonary oedema in a bipolar TURP patient. Patel et al. also expressed concern for potential problems with hypervolaemia and hyponatraemia. They suggest warming the saline solution and emptying the bladder from time to time during surgery. In our experience, no overflow syndrome occurs.

Tissue alterations In traditional monopolar resection, the tissue's electrical resistance creates temperature as high as $400^{\circ} \mathrm{C}$ which leads to desiccation with significant collateral and penetrative tissue damage [6]. High-frequency current generated by a bipolar instrument tends to remain superficial; Luciano et al. [4, 5] reported a $0.5-1-\mathrm{mm}$ depth of penetration compared with the 3-5 $\mathrm{mm}$ seen in monopolar system allowing a better control of the cut and lower possibility of accidental injury. The technique allows to maintain the current between the active electrode and the adjacent return electrode. Plasma effect of the loop prevents sticking effect onto it. In this case, tissue damage is minimised and tissue temperature range from $40^{\circ} \mathrm{C}$ to $70^{\circ} \mathrm{C}$. Improved tissue analysis secondary to reduction of carbonisation of tissue has been also reported with better histological interpretation. Improved visibility aiding the identification of surgical landmarks during procedure have been repeatedly reported.

Less bleeding during resection Optimised resection current provided by the Karl Storz Autocon II 400 allows a better coagulation during resection with reduced bleeding. Furthermore, the coagulation capacity by itself is extremely more powerful in the bipolar system in comparison with monopolar. This avoids time-consuming re-coagulation after resection for coagulation and contributes to close the superficial capillary vascularisation, also reducing intravasation.

Better visibility Minor air bubbles and less bleeding during resection allow a better vision during surgery reducing length of surgery and improving results.

Reduced costs Compatible components of existing monopolar Karl Storz resectoscopes (optics, sheaths). Resection loops are reusable and have a duration and a cost comparable with the traditional monopolar ones.

The outcomes of studies in gynaecology and urology with bipolar system demonstrate its versatility and the possibility of rapid replacement of "old" monopolar system. The bipolar system is technically superior, cost-effective and safer in comparison with the monopolar system. If we take in consideration also the medical-legal aspects, it will be very dangerous to maintain the old system, especially in case of complications. Preliminary findings of decreased morbidity using bipolar system using saline solution force us to consider others factors involved in possible complications such as duration of surgery as well as the experience of the surgeon. These variables must be included in our future investigations. However, the decrease of "theoretical risk" of overflow syndrome that give the bipolar system does not allow to avoid close peri-operative monitoring of distension medium balance and laboratory investigations.

Larger prospective randomised clinical trails examining cost-effectiveness and long-term outcome need to be performed, although it seems already very clear that this technology will replace in a near future the conventional monopolar electrosurgery.

\section{References}

1. Mencaglia L, Cavalcanti L (2004) Histeroscopia Cirùrgica. UnionTask Press, Rio de Janeiro, pp 15-28

2. Soderstrom RM (1996) Principles of eletrosurgery during endoscopy. In: Sanmarco MJ, Stovall TG, Steege JF (eds) Gynecologic endoscopy. Williams \& Wilkins, Baltimore, pp 179-192

3. Stadler KR, Woloszko J, Brown IG (2001) Repetitive plasma discharges in saline solutions. Appl Phys Lett 79:4503-4505

4. Luciano AA, Whitman G, Maier DB et al (1987) A comparison of thermal injury, healing patterns, and postoperative adhesion formation following $\mathrm{CO}_{2}$ laser and electromicrosurgery. Fert Steril 48:1025-1029

5. Luciano AA (1995) Power sources. Obstet Gynecol Clin N Am 22:423-443

6. Patel A, Adshead J (2004) First clinical experience with new transurethral bipolar prostate electrosurgery resection system: controlled tissue ablation (Coblation Technology). J Endour 18:959-964

7. Makris N, Vomvolaki E, Mantzaris G et al (2007) Role of a bipolar resectoscope in subinfertile women with submucous myomas and menstrual disorders. J Obstet Gynaecol Res 33 (6):849-854

8. Loffer FD (2004) Preliminary experience with the VersaPoint bipolar resectoscope using a vaporizing electrode in a saline distending medium. J Am Ass Gyn Lapar 7:498-502

9. Golan A, Sagiv R, Berar M et al (2001) Bipolar electrical energy in physiologic solution: a revolution in operative hysteroscopy. $\mathrm{J}$ Am Ass Gyn Lapar 8:252-258

10. Singh H, Desai M, Shrivastav P et al (2005) Bipolar versus monopolar transurethral resection of prostate: randomized controlled study. J Endour 19:333-338 
11. Wendt-Nordahl G, Hacker A, Reich O et al (2004) The Vista System: a new bipolar resection device for endourological procedures: comparison with conventional resectoscope. Eur Urol 46:86-90

12. Riedel HH, Semm K (1982) There is no place in gynecological endoscope for unipolar of bipolar high frequency current. Endoscopy 14:51-54

13. Levy BS, Soderstrom RM, Dail DH et al (1985) Bowel injuries during laparoscopy. Gross anatomy and histology. J Reprod Med 30:168-172

14. Di Giovanni M, Vasilenko P, Belsky D et al (1990) Laparoscopic tubal sterilization. The potential of thermal bowel injuries. J Reprod Med 35:951-954

15. Odell RC (1995) Electrosurgery: principles and safety issues. Clin Osbtet Gyn 38:610-621

16. Kolmer T, Norlen H (1989) Transurethral resection of the prostate: a review of 1111 cases. Int Urol Neph 21:47-55
17. Koshiba K, Egawa S, Ohori M et al (1995) T- Does transurethral resection of prostate pose a risk to life? 22 years outcome. J Urol 153:1506-1509

18. Mebust WK, Holtgrewe HL, Cockett ATK et al (1989) Transurethral prostatectomy: Immediate and postoperative complications: a cooperative study of 13 participating institutions evaluating 3885 patients. J Urol 141:243-247

19. Kudela M, Lubusky D, Dzvincuk P (1996) Risk of fluid overload syndrome during hysteroscopy procedures. Cesk Gyn 61:291-293

20. Estes CM, Maye JP (2003) Severe intraoperative hyponatremia in a patient scheduled for elective hysteroscopy: a case report. AANA J 71:203-205

21. Starkman JS, Santucci R (2005) Comparison of bipolar transurethral resection of the prostate with standard transurethral prostatectomy: shorter stay, earlier catheter removal and fewer complications. BJU Int 95:69-71 